TECHNICAL NOTE

\author{
A. Ehteshami Rad \\ L.A. Gray \\ D.F. Kallmes
}

\section{Significance and Targeting of Small, Central Clefts in Severe Fractures Treated With Vertebroplasty}

SUMMARY: We report a small cohort of patients with severe osteoporotic fractures treated with vertebroplasty. We note a high prevalence of small, central, intraosseous clefts in these severe fractures. Rather than filling the small amount of residual bone marrow around the periphery of these severe fractures, as suggested by previous authors, we suggest central needle placement to fill these central clefts.
$\mathbf{V}$ ertebroplasty, which is widely applied for the treatment of painful, osteoporotic fractures, is considered by some practitioners to be relatively contraindicated in cases of severe compression fractures. ${ }^{1-4}$ Severe fractures may present technical challenges in placing needles into the bone marrow space. Previous case series of vertebroplasty in cases of severe fracture have recommended lateral placement of 2 needles, to target the small amount of remaining marrow space around the periphery of the vertebral body. ${ }^{5-7}$

In this technical note, we describe an alternative treatment approach for severe vertebral compression fractures. For the purposes of this study, we define "severe" compression fracture as vertebrae with complete loss of height of the central aspect of the vertebral body. In the proposed alternative treatment approach, care should be taken to identify on pretreatment imaging the presence of small, intravertebral fluid cavities, commonly associated with vertebral osteonecrosis. ${ }^{8,9}$ Notwithstanding the complete loss of central vertebral body height, we recommend central needle placement in hopes of filling the small, intravertebral cleft. We present technical features and clinical outcomes in a small cohort of patients with severe vertebral compression fractures who were treated with vertebroplasty.

\section{Patients and Technique}

Institutional review board approval was obtained for this study. A retrospective review was made of a vertebroplasty data base consisting of more than 700 patients treated between February 1999 and July 2007 , to identify patients with severe compression fractures who were treated with vertebroplasty. Some of these patients had been previously included in a report of our complete vertebroplasty experience but were not separately analyzed. ${ }^{10}$ We define severe compression fracture as vertebrae with complete loss of height of the central aspect of the vertebral body. Our definition of complete collapse is that there is essentially no more height to be lost in the body. However, there still remain thin regions of fluid or air between the endplates. We identified 11 patients with 12 severe compression fractures who had undergone vertebroplasty between July 2003 and May 2007. Preprocedure imaging in these patients included plain radiographs and MR imaging of all patients and CT in 1 patient. We define the presence of an intravertebral cavity or cleft as follows: 1) an air-filled cavity on plain

Received October 9, 2007; accepted after revision November 2.

From the Department of Radiology, Mayo Clinic, Rochester, Minn.

Please address correspondence to David F. Kallmes, Mayo Clinic, 200 First St SW, Rochester, MN 55905; e-mail: kallmes.david@mayo.edu

DOI 10.3174/ajnr.A1066 radiograph, 2) an air-filled or fluid-filled cavity on CT or MR imaging, or 3) a filling pattern during vertebroplasty compatible with preexisting cleft, in which globular filling is obtained.

In typical circumstances, a transpedicular approach was performed with an 11- or 13-gauge bone biopsy needle (Osteo-Site; Cook, Bloomington, Ind) under fluoroscopic guidance. The needle tip was advanced into the vertebral cleft, if noted on preprocedure imaging, or otherwise into the central aspect of the ventral portion of the compressed vertebral body (Fig 1). In 1 patient, bilateral transpedicular injections into the lateral vertebral body were performed. Cement was infused until extraosseous extravasation was noted or until cement reached the posterior one quarter of the vertebral body.

Severity of pain at rest and with activity was measured on the basis of a semiquantitative pain scale (0-10). A 2-hour follow-up by the treating neuroradiologists as well as follow-up telephone interviews conducted by vertebroplasty nurses at 1 week, 1 month, and 6 months after the procedure were recorded.

\section{Results}

Among our 11 patients ( 8 women and 3 men), 12 severe fractures were treated ( 8 thoracic and 4 lumbar vertebrae). Mean patient age was 75 years. All patients had osteoporotic fractures. In 3 cases, patients also had myeloma, but the treated levels showed no evidence of local myelomatous disease. Three patients had nonsevere fractures treated with vertebroplasty at the same sitting as the treatment of the severe fractures. In 7 fractures, 13-gauge needles were used and in 5 fractures, 11-gauge needles were used. Clefts were present on preprocedure MR imaging in 6 of 12 fractures (Fig 2). Among the 11 cases of patients in which central needle placement was made, clefts were filled during vertebroplasty in $9(81 \%), 3$ of

\begin{tabular}{|c|c|c|c|c|}
\hline \multicolumn{5}{|c|}{ Pain relief after vertebroplasty procedure } \\
\hline & Worse & No Change & Decreased & $\begin{array}{c}\text { Completely } \\
\text { Improved }\end{array}$ \\
\hline \multicolumn{5}{|l|}{ Pain at rest } \\
\hline Postoperative (11) & 0 & 1 & 6 & 4 \\
\hline 1 week (11) & 1 & 1 & 5 & 4 \\
\hline 1 month (9) & 0 & 1 & 3 & 5 \\
\hline 6 months $(6)$ & 0 & 0 & 2 & 4 \\
\hline \multicolumn{5}{|l|}{ Pain with activity } \\
\hline Postoperative (11) & 0 & 0 & 7 & 4 \\
\hline 1 week (11) & 0 & 0 & 8 & 3 \\
\hline 1 month (9) & 0 & 0 & 6 & 3 \\
\hline 6 months $(6)$ & 0 & 0 & 5 & 1 \\
\hline
\end{tabular}

Note:-Numbers in parentheses indicate number of patients available at each follow-up time point, and numbers in each column indicate severity of pain on the basis of a semiquantitative pain scale $(0-10)$. 

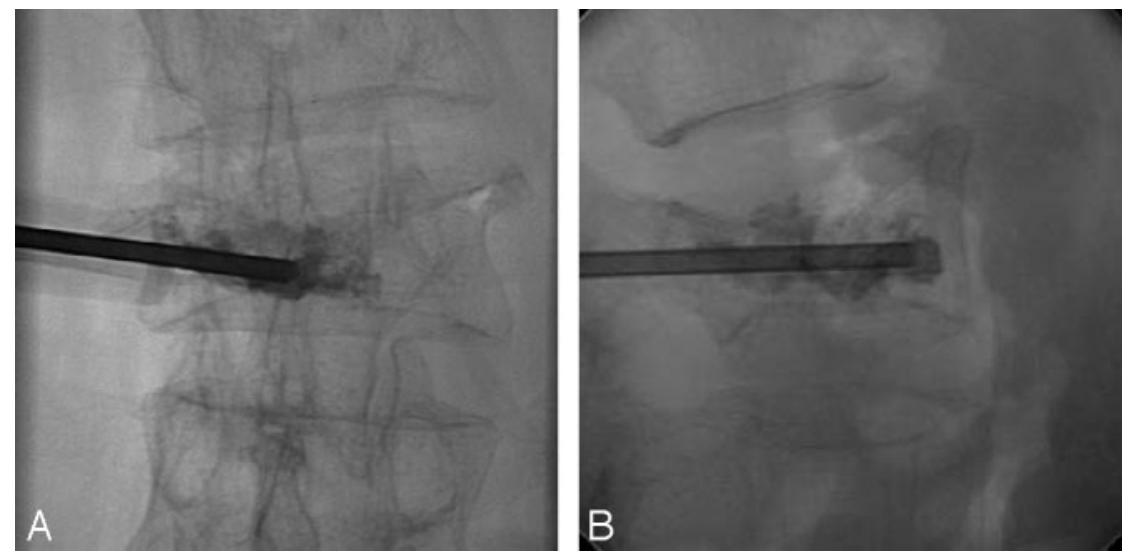

Fig 1. Anteroposterior and lateral plain radiographs during vertebroplasty at L3 show the tip of the 11-gauge cannula in the ventral aspect of the midline of the vertebral body. Barium-opacified cement fills a small ventral cleft and a small portion of the right lateral aspect of the vertebral body. with a small amount of extravasation through the superior endplate.
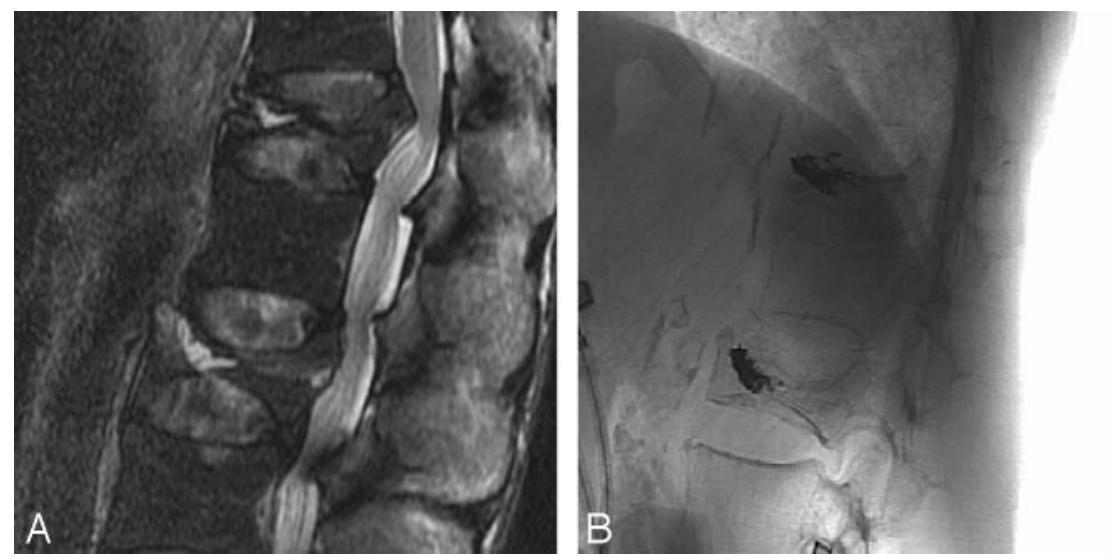

Fig 2. A, Sagittal T2-weighted MR imaging of the lumba spine shows severe fractures at T12 and L2 with fluid-filled clefts. $B$, lateral plain radiographs after vertebroplasty show cement-filled clefts corresponding with clefts seen on preprocedure MR imaging shown in $A$.
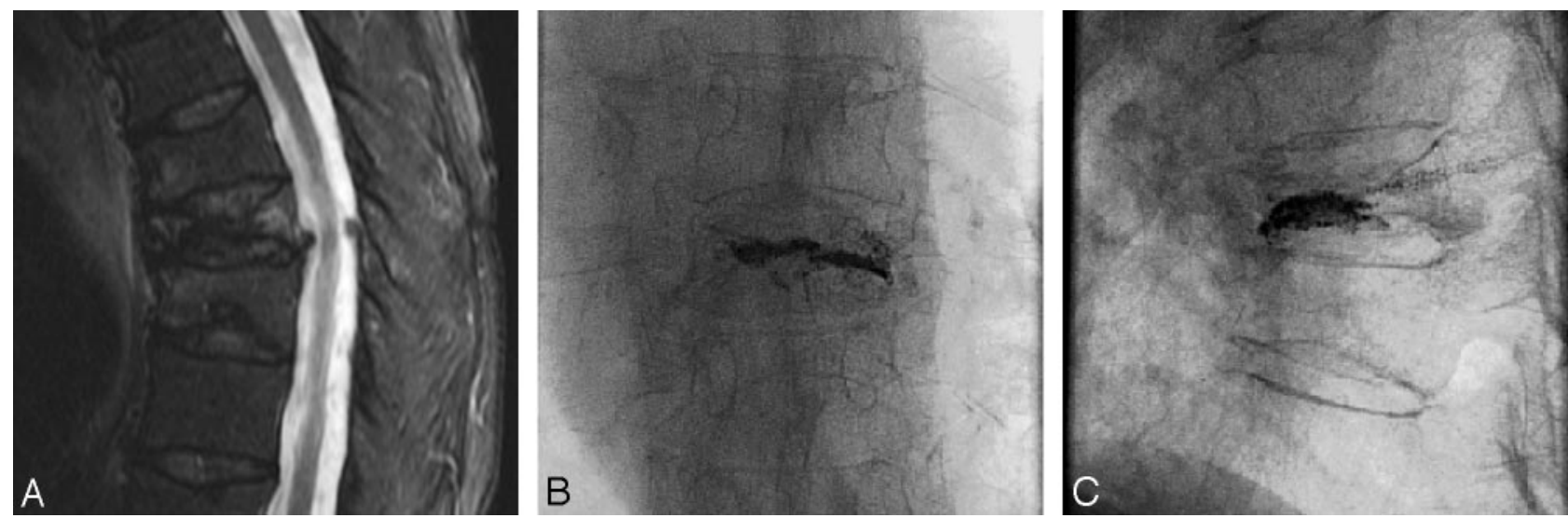

Fig 3. A, Sagittal T2-weighted MR imaging shows severe fracture at T8 without evidence of a cleft. $B$ and $C$, Anteroposterior and lateral plain radiographs after vertebroplasty show cement filling a linear cleft.

which had no cavity on preprocedure MR imaging (Fig 3). In some cases, small clefts noted on MR imaging were noted to be large when filled with cement (Fig 4).

The mean injected cement volume was $1.2 \mathrm{~mL}$ (range, $0.2-$ $2.1 \mathrm{~mL})$. Cement leakage appeared in 6 levels in very small amounts (superior endplate, 4; inferior endplate, 2) without evidence for clinical complication.

We were able to obtain follow-up in $100 \%, 80 \%$, and $55 \%$ of patients at 1 week, 1 month, and 6 months, respectively. Pain before the procedure was present for a mean of 3 months (range, 1-7 months). As shown in the accompanying Table, pain relief was obtained in 90\% (54\% partial and 36\% complete) of patients at rest and 100\% (64\% partial and 36\% com- plete) of patients with activity. The single patient who indicated no improvement at 1 month was the patient who was treated with the lateral cement infusions.

\section{Discussion}

This brief note suggests that identification and treatment of small, intraosseous clefts within severe vertebral fractures is technically feasible, safe, and is associated with good pain relief. Although only half of our cases of severe fracture showed evidence of intraosseous clefts before the vertebroplasty on MR imaging, most cases had evidence of clefts during vertebroplasty. Small amounts of cement were used, and extravasation was not problematic. Our small series may suggest not 

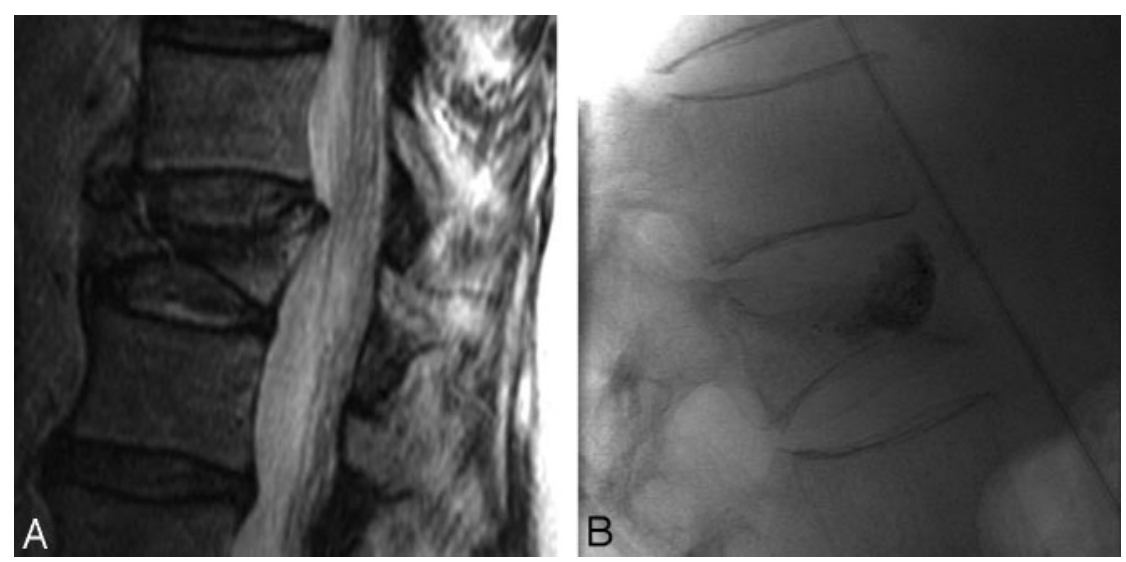

Fig 4. $A$, Sagittal T2-weighted image shows small cleft within the severe fracture at T12. $B$, Lateral plain radiograph after vertebroplasty shows filling of a large cleft.

only that patients with severe fractures are good candidates for vertebroplasty, but also that unipedicular, central needle placement can render the procedure simple, rapid, and efficacious. $^{11}$

Previous authors have noted good outcomes in patients with severe fractures who were treated with vertebroplasty. O'Brien et al proposed bipediculate injections with ".. the trocar ... placed as far laterally as possible," ${ }^{2}$ evidently to fill the residual marrow space along the periphery of the vertebral body. Although they do not mention this in their study, O'Brien et al showed 1 image (Fig 2G from O'Brien et al) in which a central cleft had been filled with cement. A large series of severe fractures Peh et $\mathrm{al}^{6}$ reported that because of “... severe central compression of the vertebra, the needle was placed more to the side of the vertebral body to decrease the chance of placing PMMA [polymethylmethacrylate] into the disk." As with the study by O'Brien et al, the study by Peh et al shows a case with a central cleft filled with cement (Fig 3 from Peh et al), but the importance or relevance of central clefts was not discussed. In contrast to these 2 previous reports, we suggest central needle placement to fill a cleft, if present, rather than lateral needle placement.

Our study had several limitations. For one, the number of patients was small. We were unable to perform any meaningful comparison between central and lateral needle placement because we only reported a single case of a patient with lateral needle placement. It is interesting to note that this single patient had not responded well at 1 month. Furthermore, use of a relatively steep oblique lateral needle approach may have been difficult in the setting of poor imaging, inexperienced operators, or distorted anatomy. Recent release of a curved infusion cannula (AVAflex; Cardinal Health, Dublin, Ohio) might have assisted in entering small clefts by using a relatively straight anteroposterior guiding needle approach.

\section{References}

1. Deramond H, Depriester C, Galibert P, et al. Percutaneous vertebroplasty with polymethylmethacrylate. Technique, indications, and results. Radiol Clin North Am 1998;36:533-46

2. Mathis JM, Petri M, Naff N. Percutaneous vertebroplasty treatment of steroidinduced osteoporotic compression fractures. Arthritis Rheum 1998;41:171-75

3. Cotten A, Boutry N, Cortet B, et al. Percutaneous vertebroplasty: state of the art. Radiographics 1998;18:311-20; discussion 320-23

4. Weill A, Chiras J, Simon JM, et al. Spinal metastases: indications for and results of percutaneous injection of acrylic surgical cement. Radiology 1996;199:241-47

5. O'Brien JP, Sims JT, Evans AJ. Vertebroplasty in patients with severe vertebral compression fractures: a technical report. AJNR Am J Neuroradiol 2000;21:1555-58

6. Peh WC, Gilula LA, Peck DD. Percutaneous vertebroplasty for severe osteoporotic vertebral body compression fractures. Radiology 2002;223:121-26

7. Hentschel SJ, Rhines LD, Shah HN, et al. Percutaneous vertebroplasty in vertebra plana secondary to metastasis. J Spinal Disord Tech 2004;17:554-57

8. Wiggins MC, Sehizadeh M, Pilgram TK, et al. Importance of intravertebral fracture clefts in vertebroplasty outcome. AJR Am J Roentgenol 2007;188:634-40

9. Ha KY, Lee JS, Kim KW, et al. Percutaneous vertebroplasty for vertebral compression fractures with and without intravertebral clefts. J Bone Joint Surg Br 2006;88:629-33

10. Layton KF, Thielen KR, Koch CA, et al. Vertebroplasty, first $\mathbf{1 0 0 0}$ levels of a single center: evaluation of the outcomes and complications. AJNR Am J Neuroradiol 2007;28:683-89

11. Kim AK, Jensen ME, Dion JE, et al. Unilateral transpedicular percutaneous vertebroplasty: initial experience. Radiology 2002;222:737-41 